\title{
Imbalance Towards Th1 Predominance Is Associated with Acceleration of Lupus-like Autoimmune Syndrome in MRL Mice
}

\author{
Satoru Takahashi, ${ }^{*}$ Liliane Fossati, ${ }^{*}$ Masahiro Iwamoto, ${ }^{*}$ Ramón Merino, ${ }^{\star}$ Roland Motta, ${ }^{\ddagger}$ Takatoshi Kobayakawa, \\ and Shozo Izui* \\ *Department of Pathology, Centre Médical Universitaire, University of Geneva, 1211 Geneva 4, Switzerland; \\ ${ }^{\ddagger}$ Institut Transgenose, 45071 Orléans, France; and ${ }^{\S}$ Department of International Affairs and Tropical Medicine, \\ Tokyo Women's Medical College, Tokyo 162, Japan
}

\begin{abstract}
To investigate the respective roles of Th1 and Th2 cells in the pathogenesis of lupus-like autoimmune disease, we have analyzed the spontaneous and antigen-induced productions of IgG1 vs IgG2a and IgG3 subclasses in relation to the mRNA expression of INF- $\gamma$ (Th1 cytokine promoting IgG2a and IgG3 production), IL-4 (Th2 cytokine promoting IgG1 production), and IL-10 (Th2 cytokine) in $\mathrm{CD}^{+}{ }^{+} \mathrm{T}$ cells from lupus-prone MRL mice. For this purpose, two paired sets of MRL mice were chosen for the comparison of these parameters: (a) MRL-lpr/lpr (lpr for lymphoproliferation) and its recently described substrain with a prolonged survival, termed MRL-lpr/lpr.ll (ll for long lived) and (b) MRL male mice bearing the Yaa (Y-linked autoimmune acceleration) gene (MRL.Yaa) with an accelerated disease and their male counterparts lacking the Yaa gene. We demonstrate herein that the accelerated development of lupus-like autoimmune disease in MRL-lpr/lpr and MRL.Yaa mice, as compared with MRL-lpr/lpr.ll and MRL-+/+ mice, respectively, was correlated with an enhanced expression of IFN- $\gamma$ vs IL-4 and IL-10 mRNA in CD4 ${ }^{+} \mathrm{T}$ cells, which paralleled with an increase of spontaneous and foreign $T$ cell-dependent antigen-induced productions of IgG2a and IgG3 vs IgG1 antibodies. These data suggest that an imbalance towards Th1 predominance may play a significant role in the acceleration of lupus-like autoimmune disease in MRL mice. (J. Clin. Invest. 1996. 97:1597-1604.) Key words: systemic lupus erythematosus • T helper subset • autoantibody - cytokine $\bullet$ mutant mice
\end{abstract}

\section{Introduction}

The MRL strain spontaneously develops an autoimmune syndrome resembling human SLE characterized by the production of various autoantibodies and the development of fatal glomerulonephritis (1). It has been shown that the progression of lupus-like autoimmune syndrome in MRL mice is markedly

\footnotetext{
Address correspondence to Dr. Shozo Izui, Department of Pathology, C.M.U., 1211 Geneva 4, Switzerland. Phone: 22-70-25-741; FAX: 22-70-25-746.

Received for publication 10 July 1995 and accepted in revised form 22 January 1996.
}

J. Clin. Invest.

(C) The American Society for Clinical Investigation, Inc. 0021-9738/96/04/1597/08 \$2.00

Volume 97, Number 7, April 1996, 1597-1604 accelerated by the presence of the $\operatorname{lpr}$ (lymphoproliferation) ${ }^{1}$ gene and the Yaa (Y-linked autoimmune acceleration) gene $(1,2)$. Although the molecular nature of the Yaa gene abnormality has not yet been identified, the $l p r$ gene was recently found to cause defects in the Fas antigen which mediates apoptosis (3). More recently, we have established a substrain of MRL-lpr/lpr mice which live almost twice as long with delayed development of glomerulonephritis, termed MRL-lpr/lpr.ll (ll for long lived), as compared with conventional MRL-lpr/lpr mice (4). Since MRL-lpr/lpr.ll mice still carry the lpr mutation, a new mutation is likely to be responsible for the retardation of the lupus-like autoimmune syndrome.

It is now well established that the lpr or Yaa gene-mediated acceleration of lupus-like autoimmune disease is dependent on the presence of $\mathrm{CD} 4^{+} \mathrm{T}$ cells (5-9). However, the respective roles of two different $\mathrm{T}$ helper cell subsets, Th1 and Th2, exhibiting different capacities of cytokine secretion, in the development and acceleration of SLE have not yet been well defined. Since several cytokines produced by Th2 cells, such as IL-4, IL-5, IL-6, and IL-10, are known to promote antibody production by B cells (reviewed in reference 10), it has been speculated that Th2 cells may play an active role in the development of autoantibody-mediated autoimmune diseases such as SLE (11). In fact, a lupus-like autoimmune syndrome occurring in mice during graft-versus-host and host-versusgraft reactions has been well documented to be a result of the selective activation of Th2 type cells (12-15). However, the cytokine generated by the Th1 cells such as IFN- $\gamma$ is also known to promote the secretion of $\operatorname{IgG} 2$ a and $\operatorname{IgG} 3$ antibodies $(10,16$, 17). In addition, the acceleration of SLE by repeated injections of recombinant IFN- $\gamma$, and inhibition by anti-IFN- $\gamma$ antibodies in $(\mathrm{NZB} \times \mathrm{NZW}) \mathrm{F} 1$ hybrid mice $(18)$ suggest the possible involvement of Th1 type cells in the spontaneous development and progression of SLE.

To assess the respective roles of Th1 and Th2 cells in the pathogenesis of SLE, we have analyzed the expression of IFN- $\gamma$, IL-4, and IL-10 mRNA in CD4 ${ }^{+} \mathrm{T}$ cells from lupusprone MRL mice in relation to the production of $\mathrm{IgG}$ subclasses. To better compare these parameters, we have chosen two paired sets of MRL mice, i.e. (a) MRL-lpr/lpr and its substrain MRL-lpr/lpr.ll with a prolonged survival and (b) MRL male mice bearing the Yaa gene (MRL.Yaa) with an accelerated disease and their male counterparts lacking the $Y a a$ gene $(\mathrm{MRL}-+/+)$; this is because serum levels of total $\mathrm{IgG}$ are al-

1. Abbreviations used in this paper: AHGG, aggregated HGG; DN, double negative; GAPDH, glyceraldehyde-3-phosphate dehydrogenase; HGG, human IgG; $l l$, long lived; $l p r$, lymphoproliferation; RDU, relative densitometric unit; RT, reverse transcriptase; Yaa, Y-linked autoimmune acceleration. 
most comparable between MRL-lpr/lpr and MRL-lpr/lpr.ll mice and between MRL.Yaa male and MRL-+/+ male mice, yet the progression of lupus-like autoimmune disease markedly differs between these two pairs of MRL mice $(2,4)$. We report herein that the acceleration of autoimmune disease in MRL-lpr/lpr or MRL.Yaa mice is correlated with an increased production of IgG2a and IgG3 vs IgG1 autoantibodies in parallel to an enhanced expression of IFN- $\gamma$ vs IL-4 and IL-10 mRNA in $\mathrm{CD}^{+} \mathrm{T}$ cells, suggesting an involvement of Th1 type cells in the acceleration of lupus-like autoimmune disease in MRL mice.

\section{Methods}

Mice. MRL-lpr/lpr mice were originally obtained from the Jackson Laboratory in 1978 and were maintained at Centre de Service des Animaux de Laboratoire (Orléans, France). In 1988, offspring of a single pair of long-lived male and female MRL-lpr/lpr founder mice were bred by brother-sister mating. At the sixth generation, a subline with a prolonged survival, referred to as MRL-lpr/lpr.ll, was obtained (4). MRL-+/+ mice were purchased from Olac Laboratory, Oxon, UK. MRL.Yaa mice bearing the Yaa gene were developed by transferring the Yaa gene from BXSB mice into MRL-+/+ mice by backcross procedure as described (2). All lines of MRL mice have been kept under the same condition and only male mice were used for the present study. Mice were bled from the retroorbital plexus, and resulting sera were stored at $-20^{\circ} \mathrm{C}$ until use.

Immunization. Human IgG (HGG) was heat-aggregated at $63^{\circ} \mathrm{C}$ for $30 \mathrm{~min}$. Mice were immunized with an intravenous injection of 400 $\mu \mathrm{g}$ of heat-aggregated HGG (AHGG) in PBS. $10 \mu \mathrm{g}$ of pneumococcal capsular polysaccharide antigen (Pneumovax-23; Merck Sharp \& Dohme, West Point, PA) in PBS were intraperitoneally injected.

Serological assays. Serum levels of IgG subclasses were determined by ELISA as described (19). Briefly, rabbit anti-IgG subclassspecific antibodies (Litton Bionetics Inc., Kensington, MD) were used for coating the plates, and the assays were developed with the same corresponding antibodies conjugated with alkaline phosphatase. Results are expressed in $\mathrm{mg} / \mathrm{ml}$ in reference to a standard curve obtained with mouse Ig reference serum (ICN ImmunoBiologicals, Costa Mesa, CA). IgM, IgG1, IgG2a, and IgG3 anti-DNA, antiHGG, and anti-polysaccharide antibodies were measured by ELISA using anti-IgM (LO-MM-9) (20), anti-IgG1 (Ig[4a]10.9) (21), antiIgG2a (Ig[1a]8.3) (21) and anti-IgG3 (H139.61.1) (22) mAbs conjugated with alkaline phosphatase. Monospecificities of these $\mathrm{mAb}$ against IgM and IgG subclasses of MRL mice ( $\operatorname{Igh}^{\mathrm{j}}$ ) were confirmed by anti-DNA ELISA using different Ig isotypes of anti-DNA mAb derived from MRL-lpr/lpr mice. Results are expressed in titration units $(\mathrm{U} / \mathrm{ml})$ in reference to standard curves obtained from anti-DNA mAb of different $\mathrm{IgG}$ subclasses and from CBA/J mice (Igh $\mathrm{I}^{\mathrm{j}}$ immunized with foreign antigens (HGG and polysaccharides).

Purification of $\mathrm{CD}^{+}$and $\mathrm{CD}^{-} \mathrm{CD} 8^{-}$double negative (DN) $\mathrm{T}$ cells and depletion of $T$ cells. Single cell suspensions were prepared from a pool of axillary, mediastinal, retroperitoneal, and inguinal lymph nodes. To purify $\mathrm{CD}^{+}{ }^{+} \mathrm{T}$ cells, lymph node cells were stained with a rat anti-CD4 (H129.19) $\mathrm{mAb}$, followed by goat anti-rat IgG FITC conjugates, and then sorted with a FACStar (Becton Dickinson, Mountain View, CA). Thy $-1^{+} \mathrm{CD}^{-} \mathrm{CD} 8^{-} \mathrm{DN}$ T cells, a characteristic phenotype expanding in lymph nodes of MRL-lpr/lpr mice (23), were sorted after staining lymph node cells with a rat anti-Thy$1.2(30-\mathrm{H} 12) \mathrm{mAb}$, followed by goat anti-rat IgG FITC conjugates, and then incubated with biotinylated anti-CD4 (H129.19) and antiCD8 (H35-17.2) mAb, followed by phycoerythrin-conjugated avidin (Caltag Laboratories, San Francisco, CA). Cytofluorometric analysis on FACScan revealed that purified $\mathrm{CD}^{+}$and $\mathrm{DN}$ cell populations contained $<5 \%$ contaminating cells. To deplete $\mathrm{T}$ cells, lymph node or spleen cells were treated with a rat anti-Thy-1.2 (AT-83) mAb and rabbit complement. The efficiency of the treatment was documented by cytofluorometric analysis.

Reverse transcriptase $(R T)-P C R$. Total cellular RNA from lymph nodes and sorted lymph node cells were extracted by the guanidine isothiocyanate/ $\mathrm{CsCl}$ method (24) and acid guanidinium thiocyanatephenol-chloroform method (25), respectively. RNA was retrotranscribed after annealing with $1 \mu \mathrm{M}$ oligo-dT primers $(15 \mathrm{mer})$ in the presence of $100 \mathrm{U}$ of RT (Life Technology Inc., Gaithersburg, MD), $20 \mathrm{U}$ of RNAsin (Boehringer Mannheim, Mannheim, Germany), $10 \mathrm{mM}$ DTT, and $500 \mathrm{nM}$ each deoxynucleotide (Boehringer Mannheim) in a total volume of $20 \mu \mathrm{l}$ for $1 \mathrm{~h}$ at $37^{\circ} \mathrm{C}$. Aliquots of the mixture were then amplified in a thermocycler (Perkin-Elmer Corp., Norwalk, CT) in a volume of $50 \mu \mathrm{l}$ with $20 \mathrm{U} / \mathrm{ml}$ of Taq polymerase (Boehringer Mannheim), $200 \mu \mathrm{M}$ of each deoxynucleotide and $200 \mathrm{nM}$ of each of the two primers. The cycling conditions were $0.5 \mathrm{~min}$ at $94^{\circ} \mathrm{C}$ for denaturation, $1.5 \mathrm{~min}$ at $55^{\circ} \mathrm{C}$ for annealing and $1.5 \mathrm{~min}$ at $72^{\circ} \mathrm{C}$ for elongation, and then $5 \mathrm{~min}$ at $72^{\circ} \mathrm{C}$ after the last cycle. Based on results obtained by titrations of cycle number which gave a logarithmic increase in the amount of specific amplified products, samples were amplified at 32 cycles for IFN- $\gamma$, IL-4, and IL-12 and at 25 cycles for glyceraldehyde-3-phosphate dehydrogenase (GAPDH). The primers had the following sequences, $5^{\prime}$ and $3^{\prime}$ primers, respectively: IFN- $\gamma, 5^{\prime}$-TGAACGCTACACACTGCATCTTGG-3' and $3^{\prime}$-CGACTCCTTTTCCGCTTCCTGAG-5'; IL-4, 5'-GTCTCTCGTCACTGACGGC-3' and 3'-CATGGTGGCTCAGTACTA-5'; IL-10, 5'-TCAAACAAAGGACCAGCTGGACAACATACTG-3' and 3'-CTGTCTAGGTCCTGGAGTCCAGCAGACTCAA-5'; IL-12 (p40), 5'-CAACATCAAGAGCAGTAGCA-3' and $3^{\prime}$-GCATGAGGAATTGTAATAGC-5'; GAPDH, 5'-TGAAGGTCGGTGTGAACGGATTTGG-3' and 3'ACGACATACTCAGCACCAGCATCAC-5'. The primer pairs used were designed to span over introns to avoid the amplification of potential contaminating genomic DNA. PCR products were visualized after electrophoresis through $2 \%$ agarose gels by staining with ethidium bromide. The product generated by IFN- $\gamma$ primers is 460 bp, by IL- 4 primers is $459 \mathrm{bp}$, by IL- 10 primers is $420 \mathrm{bp}$, by IL-12 primers is $517 \mathrm{bp}$, and by GAPDH primers is $277 \mathrm{bp}$. To ensure the absence of sample contamination, a reaction mixture with no added cDNA was run in parallel with each PCR.

Dot blot analysis. Serially diluted amplified PCR products were blotted to nylon membranes (GeneScreen Plus; Dupont Co., Boston, MA). Hybridization was carried out under high stringency with a fulllength mouse IFN- $\gamma$ cDNA (a kind gift of Dr. W. Fiers, Ghent, Belgium), mouse IL-4 cDNA (pSP6KmIL-4374 [26]) and PCR amplified IL-10, IL-12, and GAPDH fragments, which were subcloned into pUC119 vector and verified by nucleotide sequencing, were used for preparing ${ }^{32} \mathrm{P}$-labeled probes. Quantification was performed by densitometric analysis on dot blots (Image Quant Software FAST SCAN; Molecular Dynamics Ltd., Kemsing, UK). The ratios of IFN- $\gamma$ to IL-4 or IL-10 mRNA are referred to as relative densitometric units (RDU).

Statistical analysis. Statistical analysis was performed with the Wilcoxon two-sample test. Probability values $>5 \%$ were considered insignificant.

\section{Results}

Enhanced serum levels of IgG2a and IgG3 vs IgG1 in MRL mice with an accelerated lupus-like autoimmune disease. The presence of the $l p r$ mutation markedly shortens the life span of MRL male mice as a result of the accelerated development of lethal lupus-like nephritis (1). This was accompanied by a remarkable increase in serum levels of all the IgG subclasses and by the enhanced production of a large spectrum of autoantibodies, as compared with MRL-+/+ mice $(27,28)$. However, MRL-lpr/lpr.ll mice, a recently described substrain of MRL- 
Table I. 50\% Mortality Rates and Serum Levels of IgG in Four Different Lines of MRL Male Mice

\begin{tabular}{|c|c|c|c|c|c|c|}
\hline Genotype & $50 \%$ Mortality* & Total $\mathrm{IgG}^{\ddagger}$ & IgG1 & $\operatorname{IgG} 2 \mathrm{a}$ & $\operatorname{IgG} 2 b$ & $\mathrm{IgG} 3$ \\
\hline$l p r / l p r$ & $6 \mathrm{mo}$ & $58.7 \pm 19.9$ & $9.6 \pm 3.5^{8}$ & $41.2 \pm 17.3^{\S}$ & $3.1 \pm 1.3$ & $4.7 \pm 2.4^{\S}$ \\
\hline lpr/lpr.ll & $12 \mathrm{mo}$ & $50.3 \pm 11.9$ & $18.3 \pm 8.2^{\S}$ & $27.1 \pm 8.6^{\S}$ & $2.9 \pm 1.0$ & $1.7 \pm 0.7^{\S}$ \\
\hline Yaa & $12 \mathrm{mo}$ & $25.5 \pm 9.7^{\S}$ & $7.9 \pm 2.2$ & $15.7 \pm 7.2^{\S}$ & $0.6 \pm 0.1$ & $1.4 \pm 0.9^{\S}$ \\
\hline$+1+$ & $18 \mathrm{mo}$ & $16.6 \pm 5.3^{\S}$ & $7.2 \pm 2.0$ & $8.2 \pm 3.2^{\S}$ & $0.5 \pm 0.1$ & $0.7 \pm 0.3^{\S}$ \\
\hline
\end{tabular}

* $50 \%$ mortality rate due to glomerulonephritis. ${ }^{\ddagger}$ Serum levels of total $\operatorname{IgG}$ (addition of all the IgG subclasses) and IgG subclasses in MRL-lpr/lpr and MRL-lpr/lpr.ll male mice at 4 mo of age (18 mice in each group) and in MRL.Yaa and MRL-+/+ male mice at 6 mo of age (16 mice in each group). Results are expressed in $\mathrm{mg} / \mathrm{ml}( \pm 1 \mathrm{SD}) .{ }^{\S} P<0.001$.

lpr/lpr mice with a prolonged survival (4), exhibited hypergammaglobulinemia and autoantibody production at an extent comparable to that of conventional MRL-lpr/lpr mice, yet their development of lupus-like nephritis was markedly retarded (Table I). Although serum levels of total IgG did not significantly differ between MRL-lpr/lpr and MRL-lpr/lpr.ll mice at 4 mo of age $(P>0.1)$, the analysis of $\mathrm{IgG}$ subclasses showed 1.5-fold and threefold increases in IgG2a and IgG3, respectively, but a twofold decrease in IgG1 in MRL-lpr/lpr mice, as compared with MRL-lpr/lpr.ll mice $(P<0.001)$ (Table 1). Similarly, serum levels of IgG2a and IgG3 anti-DNA autoantibodies in MRL-lpr/lpr mice were significantly higher than those of MRL-lpr/lpr.ll mice $(P<0.001)$, while IgG1 antiDNA antibody levels were diminished in MRL-lpr/lpr mice $(P<0.001)$ (Table II). Consequently, when relative concentrations of $\mathrm{IgG} 2 \mathrm{a}$ and $\mathrm{IgG} 3$ anti-DNA antibodies vs IgG1 antiDNA antibodies were analyzed in individual animals, the differences between MRL-lpr/lpr and MRL-lpr/lpr.ll mice were highly significant $(P<0.001)$ (Fig. 1). However, no differences in ratios of $\mathrm{IgG} 2 \mathrm{a} / \mathrm{IgG} 3$ anti-DNA antibodies were observed in both MRL-lpr/lpr mice $(P>0.1)$.

The Yaa gene accelerated the progression of lupus-like autoimmune syndrome in MRL mice, as documented by early development of lethal glomerulonephritis, although to a lesser extent than that induced by the lpr gene (2). MRL.Yaa male mice had moderately but significantly increased concentrations of total $\mathrm{IgG}$ in their sera at 6 mo of age, as compared with MRL- $+/+$ males lacking the Yaa gene $(P<0.001)$ (Table I). The analysis of IgG subclass concentrations revealed that sera from MRL.Yaa male mice had twofold higher levels of IgG2a and IgG3 than those from MRL- $+/+$ male mice $(P<0.001)$,

Table II. Serum Levels of IgG1, IgG2a and IgG3 Anti-DNA Autoantibodies in Four Different Lines of MRL Male Mice

\begin{tabular}{lccc}
\hline Genotype & IgG1 & IgG2a & IgG3 \\
\hline lpr/lpr & $70 \pm 88^{\ddagger}$ & $405 \pm 329^{\ddagger}$ & $169 \pm 113^{\ddagger}$ \\
lpr/lpr.ll & $263 \pm 199^{\ddagger}$ & $271 \pm 222^{\ddagger}$ & $78 \pm 60^{\ddagger}$ \\
Yaa & $39 \pm 36^{\S}$ & $73 \pm 37$ & $53 \pm 35^{\S}$ \\
$+/+$ & $62 \pm 16^{\S}$ & $67 \pm 23$ & $29 \pm 18^{\S}$ \\
\hline
\end{tabular}

Serum levels of IgG1, IgG2a, and IgG3 anti-DNA antibodies in MRLlpr/lpr and MRL-lpr/lpr.ll male mice at 4 mo of age (18 mice in each group) and in MRL.Yaa and MRL-+/+ male mice at 6 mo of age (16 mice in each group). Results are expressed in $\mathrm{U} / \mathrm{ml}( \pm 1 \mathrm{SD}) .{ }^{\ddagger} P<$ $0.001 ;{ }^{\S} P<0.05$. while levels of $\operatorname{IgG} 1$ and $\operatorname{IgG} 2 \mathrm{~b}$ were comparable $(P>0.05)$ (Table I). Comparison of serum levels of anti-DNA IgG subclasses showed relatively limited differences in IgG1 and IgG3 anti-DNA $(P<0.05)$, but not in IgG2a anti-DNA autoantibodies $(P>0.1)$ (Table II). However, the analysis of relative concentrations of anti-DNA IgG subclasses in individual animals disclosed that MRL.Yaa mice exhibited highly enhanced ratios of IgG2a/IgG1 and IgG3/IgG1 anti-DNA antibodies, as compared with those of MRL-+/+ males (Fig. $1 ; P<0.001$ ). Ratios of $\mathrm{IgG} 2 \mathrm{a} / \mathrm{IgG} 3$ anti-DNA antibodies did not significantly differ in both MRL male mice $(P>0.05)$.

Enhanced expression of IFN- $\gamma$ vs IL-4 and IL-10 mRNA by $C D 4^{+} T$ cells in MRL mice with an accelerated lupus-like autoimmune disease. The demonstration of an increased production of IgG2a and IgG3 vs IgG1 in association with an accelerated lupus-like autoimmune disease in MRL mice bearing the $l p r$ or $Y a a$ gene raised a possibility that these differences in IgG subclass expression may be related to differential activation of Th1 vs Th2 type cells during the course of autoimmune
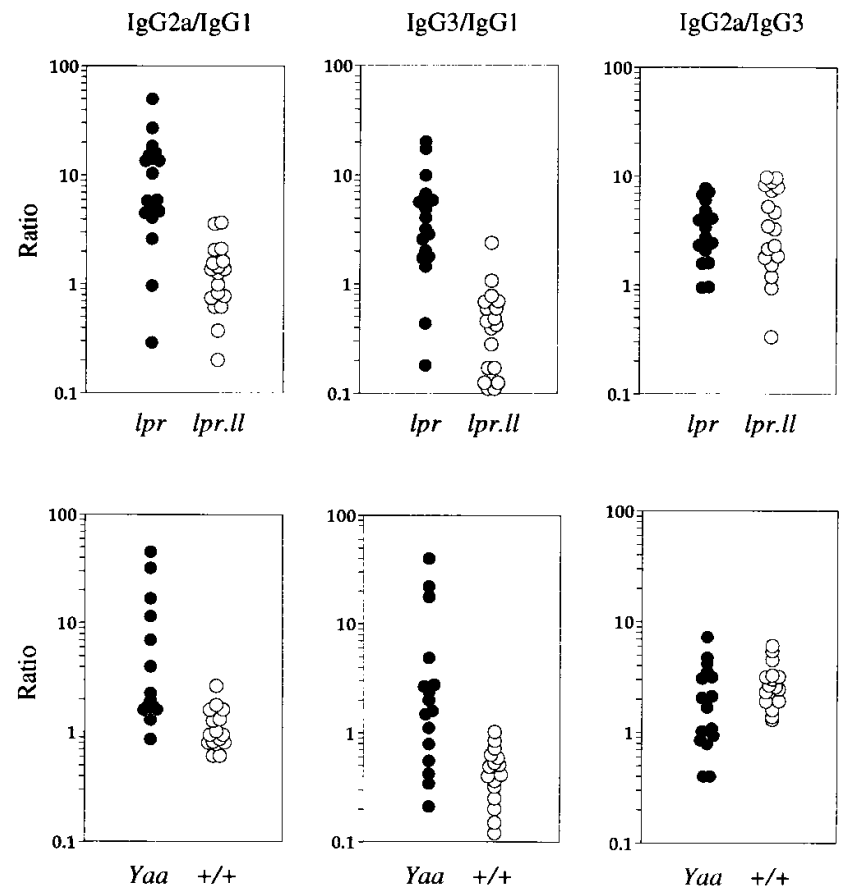

Figure 1. Relative concentrations of $\operatorname{IgG} 2 \mathrm{a} / \mathrm{IgG} 1, \mathrm{IgG} 3 / \mathrm{IgG} 1$, and $\mathrm{IgG} 2 \mathrm{a} / \mathrm{IgG} 3$ anti-DNA antibodies in individual sera from 4-mo-old MRL-lpr/lpr and MRL-lpr/lpr.ll male mice and in sera from 6-mo-old MRL.Yaa and MRL-+/+ male mice. 
A

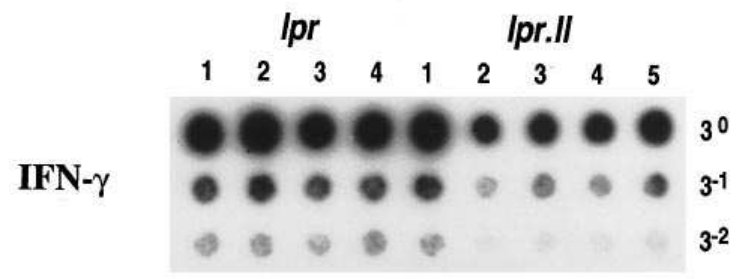

IL-4

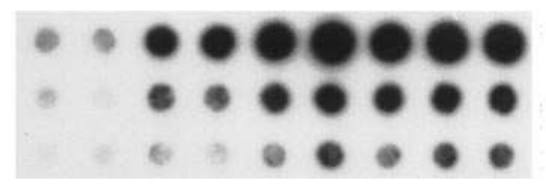

IL-10

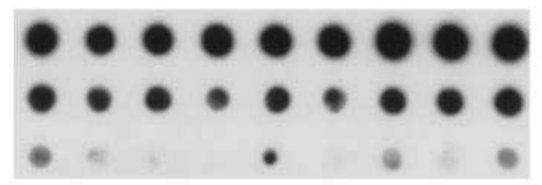

IL-12

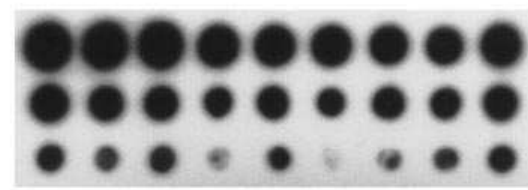

GAPDH

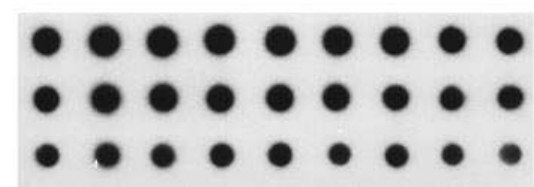

B

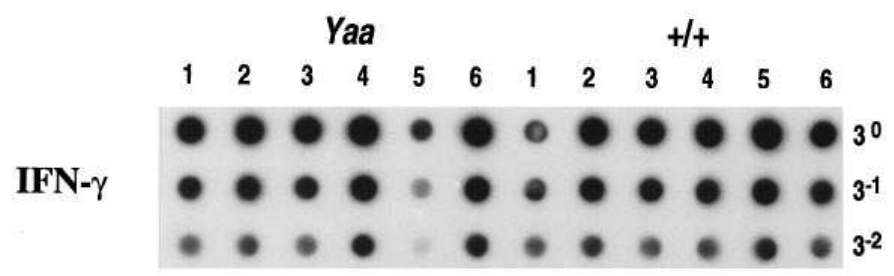

IL-4

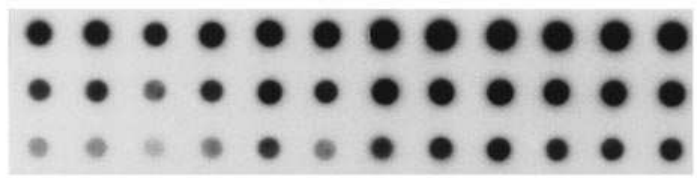

IL-10

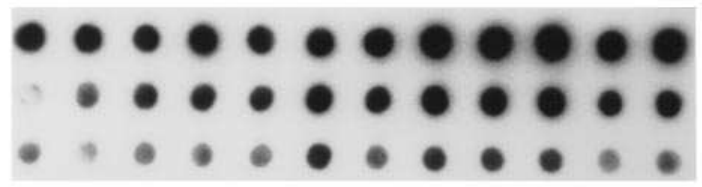

IL-12

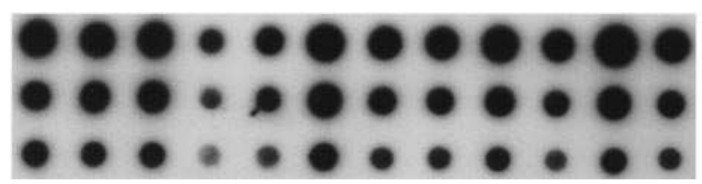

GAPDH

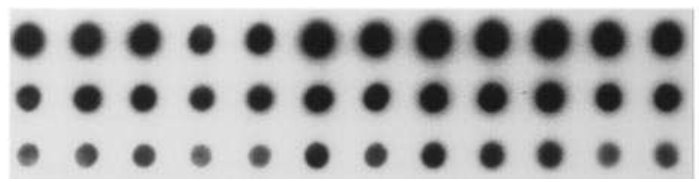

Figure 2. Dot blot analysis of IFN- $\gamma$, IL-4, IL-10, IL-12, and GAPDH mRNA expression in lymph node cells from 4 month-old MRL-lpr/lpr and MRL-lpr/lpr.ll male mice $(A)$ and from 6-mo-old MRL.Yaa and MRL-+/+ male mice $(B)$. PCR was performed with cDNA samples from individual mice (four to six mice in each group). Reciprocally diluted samples $(1.2,0.4$, and $0.13 \mu \mathrm{l}$ of the PCR mix) from amplified PCR products were applied to nylon membranes and hybridized with corresponding probes.

disease in MRL mice. To address this question, we used the RT-PCR and dot blot analysis to compare the in vivo expression of Th1 cytokine (IFN- $\gamma$ ) and Th2 cytokine (IL-4 and IL-10) mRNA in lymph node cells from different lines of MRL mice.

Comparative measurements of IFN- $\gamma$ and IL-4/IL-10 mRNA expression in 4-mo-old MRL mice bearing the lpr mutation revealed that lymph nodes from MRL-lpr/lpr mice had $\sim$ threefold higher IFN- $\gamma$ signals than those from MRL-lpr/ lpr.ll mice (Fig. 2). In contrast, levels of IL-4 transcripts were conversely diminished in MRL-lpr/lpr mice, which were about three to ninefold lower than those of MRL-lpr/lpr.ll mice, although no significant differences in IL-10 mRNA abundance were observed between these two lpr mice. However, densitometric measurements of dot blots revealed that in all MRLlpr/lpr mice tested, relative expression of IFN- $\gamma$ vs IL-10 mRNA as well as IFN- $\gamma$ vs IL-4 mRNA was significantly elevated, as compared with MRL-lpr/lpr.ll mice $(P<0.01)$ (Fig. 3).

In MRL.Yaa and MRL- $+/+$ male mice at 6 mo of age, the expression of IFN- $\gamma$ mRNA in total lymph node cells was almost comparable, while MRL-+/+ lymph nodes exhibited approximately threefold increased levels of IL-4 and IL-10 spe- cific mRNA (Fig. 2). Semiquantitatively, relative expression of IFN- $\gamma$ vs IL-4 and IL-10 mRNA was highly enhanced in 5 of 6 MRL.Yaa mice tested, as compared with that in MRL-+/+ mice $(P=0.025)$ (Fig. 3).

To confirm that the observed differences in IFN- $\gamma$, IL-4, and IL-10 mRNA expression was due to a differential activation of Th1 vs Th2 type cells in MRL-lpr/lpr and MRL.Yaa mice having an accelerated disease, a similar analysis was performed on $\mathrm{CD}^{+} \mathrm{T}$ cells purified from their lymph nodes. Both $\mathrm{CD}^{+}{ }^{+} \mathrm{T}$ cells from MRL-lpr/lpr and MRL.Yaa mice again exhibited an upregulated expression of IFN- $\gamma$ vs IL-4 and IL-10 mRNA, as compared with those from MRL-lpr/lpr.ll and MRL-+/+ mice, respectively (Fig. 3 and 4).

In addition to $\mathrm{CD} 4^{+} \mathrm{T}$ cells, we assessed the contribution of the $l p r$ DN T cells, a major subpopulation of $\mathrm{T}$ cells in $l p r$ lymph nodes, to the IFN- $\gamma$, IL-4, and IL-10 mRNA expression. Both DN T cells from MRL-lpr/lpr and MRL-lpr/lpr.ll mice expressed IFN- $\gamma$ and IL-10 mRNA at comparable levels, but failed to express detectable amounts of IL-4 mRNA (Fig. 4).

Since it has been recently shown that IL-12 plays an important role in inducing the generation of Th1 type cells from the Th0 cells (29), the expression of IL-12 mRNA in lymph node 

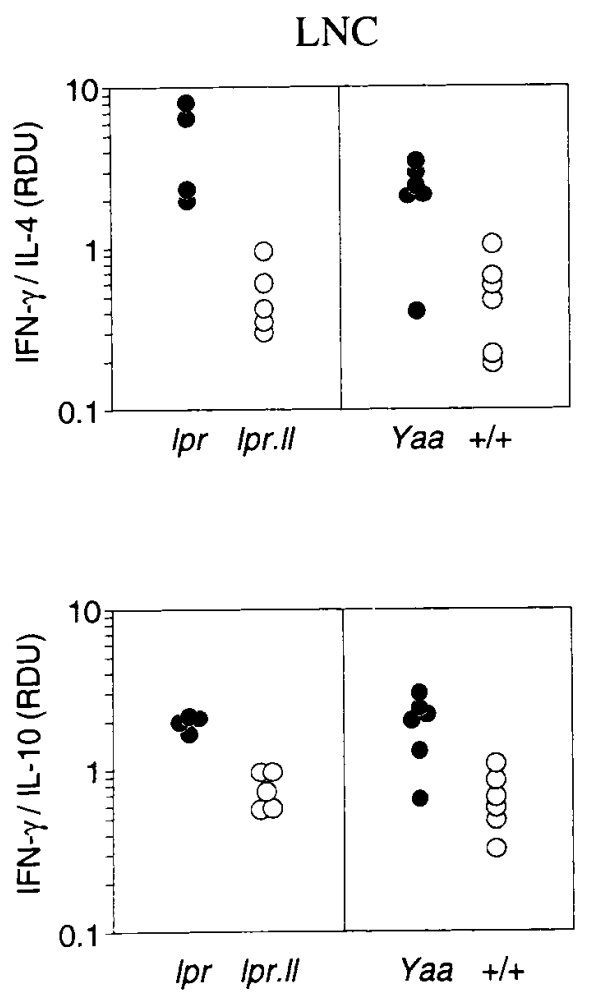
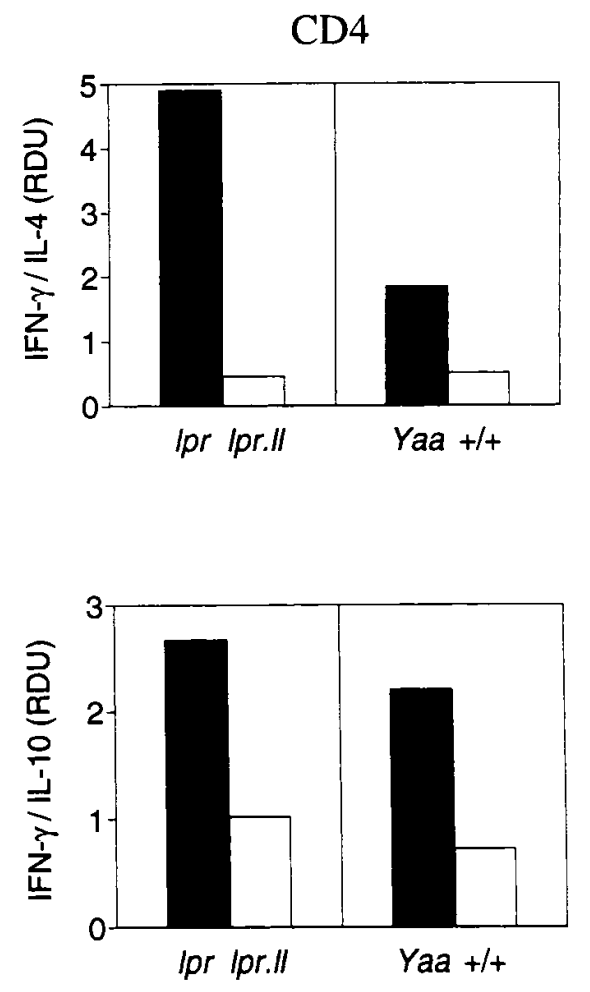

Figure 3. Comparison of relative expression of IFN- $\gamma$ vs IL- 4 and IL-10 mRNA in lymph node cells $(L N C)$ and purified $\mathrm{CD} 4^{+} \mathrm{T}$ cells $(C D 4)$ between 4-mo-old MRL-lpr/lpr and MRL-lpr/lpr.ll male mice and between 6-mo-old MRL.Yaa and MRL-+/+ male mice. The levels of each PCR products were quantified by densitometric measurement of dot blots. The ratios of IFN- $\gamma$ mRNA to IL-4 or IL-10 mRNA for individual samples are referred to as RDU. Differences between MRL$l p r / l p r$ and MRL-lpr/lpr.ll lymph node cells and between MRL.Yaa and MRL-+/+ lymph node cells are significant $(P=0.025$ and $P<0.01$, respectively). For $\mathrm{CD} 4^{+} \mathrm{T}$ cells, representative results of three separate experiments are shown. cells was determined by RT-PCR combined with dot blot analysis. No significant increased expression of IL-12 mRNA, in relation to the GAPDH mRNA expression, was observed in lymph nodes from MRL-lpr/lpr or MRL.Yaa mice, as compared with those from MRL-lpr/lpr.ll or MRL-+/+ mice (Fig. 2). No IL-12 transcripts were detected in purified $\mathrm{CD}^{+} \mathrm{T}$ and DN T cells (Fig. 4). Since the lpr DN T cells did not express IL-12 mRNA, the absent differences in IL-12 mRNA expression between MRL-lpr/lpr and MRL-lpr/lpr.ll mice may be due to a massive accumulation of the $l p r$ DN T cells in their lymph nodes. However, this possibility was unlikely, because IL-12 mRNA levels in lymph node or spleen cells depleted of $\mathrm{T}$ cells were comparable in both $l p r$ mice (data not shown). Notably, levels of IL-12 mRNA in T cell-depleted lymph node or spleen cells did not differ between MRL.Yaa and MRL-+/+ mice (data not shown).

Enhanced production of IgG2a vs IgG1 antibodies against $T$ cell-dependent foreign antigens in MRL-lpr/lpr and MRL.Yaa mice. To further assess an enhanced activity of Th1 type cells in MRL-lpr/lpr vs MRL-lpr/lpr.ll mice and in MRL.Yaa vs MRL- $/+$ mice, we determined whether the immunization with $\mathrm{T}$ cell-dependent foreign antigens led to an increased production of IgG2a vs IgG1 antibodies. 2-mo-old MRL male mice were immunized with AHGG in PBS in order to avoid any effects of Freund's adjuvant on the expression of Th1 and Th2 phenotypes. An intravenous injection of AHGG induced primary IgG anti-HGG antibody responses at comparable levels in all four lines of MRL mice (data not shown). However, the analysis of IgG1 and IgG2a anti-HGG antibodies revealed that MRL-lpr/lpr and MRL.Yaa mice produced higher titers of IgG2a anti-HGG antibodies than MRL-lpr/lpr.ll and MRL-+/+ mice (Fig. 5). This markedly contrasted with a limited production of IgG1 anti-HGG antibodies in MRL-lpr/lpr and
MRL.Yaa mice, as compared with MRL-lpr/lpr.ll and MRL-+/+ mice. In contrast, when MRL.Yaa and MRL-+/+ mice were immunized with a $\mathrm{T}$ cell-independent pneumococcal capsular polysaccharide, both males developed comparable titers of IgM (MRL.Yaa, 98 $\pm 21 \mathrm{U} / \mathrm{ml}$; MRL- $+/+, 111 \pm 31 \mathrm{U} / \mathrm{ml}$ ) and

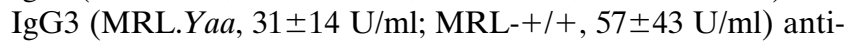
polysaccharide antibodies 7 and $14 \mathrm{~d}$ after immunization, respectively.

\section{Discussion}

In the present study, to assess the respective roles of Th1 and Th2 type cells in the acceleration of lupus-like autoimmune disease occurring in MRL mice bearing the lpr or Yaa gene, we have analyzed the spontaneous and foreign antigen-induced production of $\mathrm{IgG}$ subclasses in relation to the expression of Th1 cytokine (IFN- $\gamma$ ) and Th2 cytokine (IL-4 and IL-10) mRNA by using RT-PCR. We demonstrate herein that the accelerated development of lupus-like autoimmune disease in MRL-lpr/lpr and MRL.Yaa mice, as compared with MRL-lpr/ lpr.ll and MRL-+/+ mice, respectively, is well correlated with an enhanced expression of IFN- $\gamma$ vs IL- 4 and IL-10 mRNA in $\mathrm{CD} 4^{+} \mathrm{T}$ cells, which parallels to an increase of spontaneous and foreign $\mathrm{T}$ cell-dependent antigen-induced productions of IgG2a and IgG3 vs IgG1. Our results suggest that an imbalance towards Th1 predominance may play a role in the acceleration of lupus-like autoimmune disease in MRL mice bearing the lpr or Yaa mutation.

This conclusion is based on the fact that relative expression of IFN- $\gamma$ vs IL- 4 and IL-10 mRNA, as determined by RT-PCR in combination with a semiquantitative dot blot analysis, is highly enhanced in whole lymph nodes as well as $\mathrm{CD} 4^{+} \mathrm{T}$ cells from MRL-lpr/lpr or MRL.Yaa mice, as compared to appro- 
A
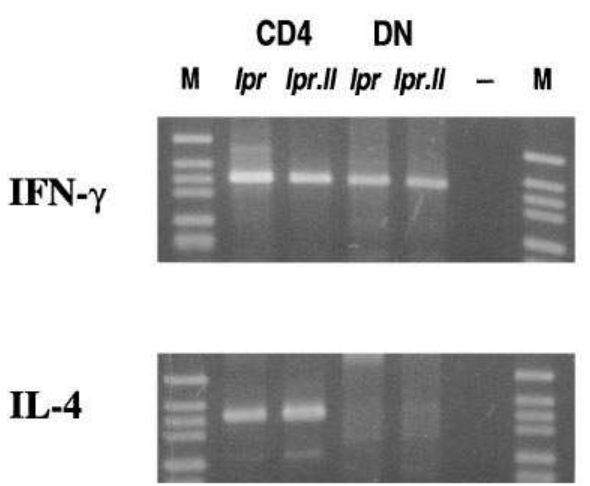

IL-4

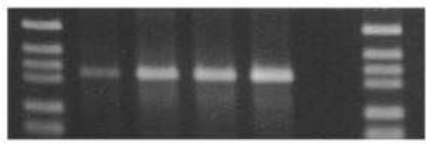

IL-10

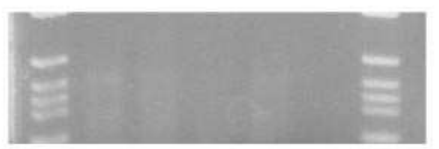

IL-12

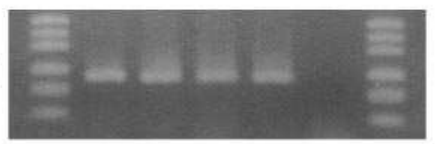

CD4 DN Ipr Ipr.II Ipr Ipr.II
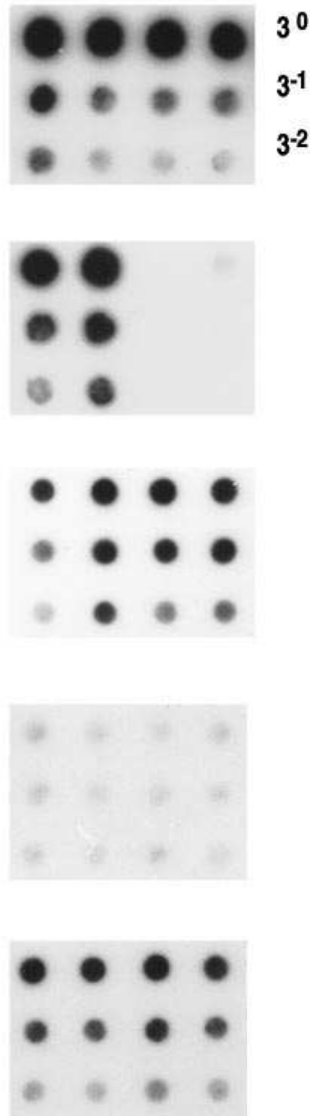

B

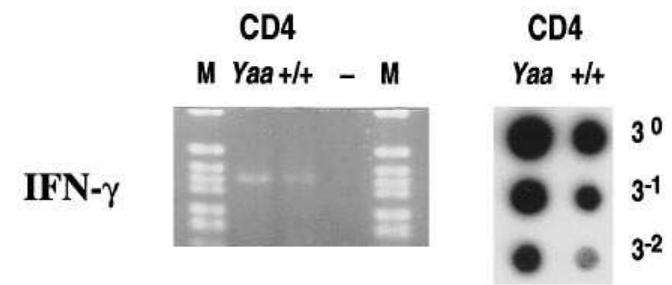

IL-4
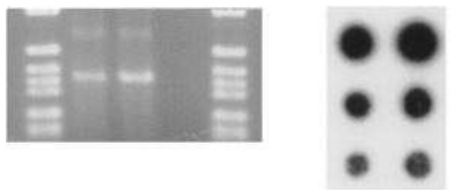

IL-10
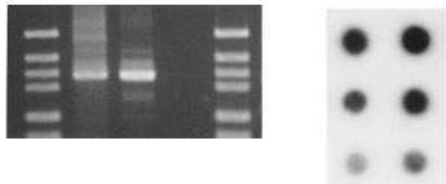

IL-12
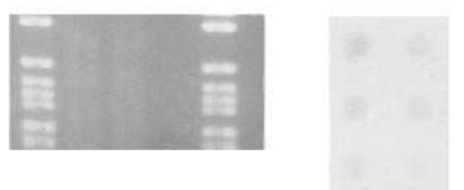

GAPDH
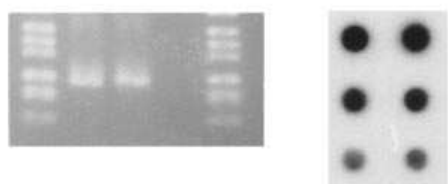

Figure 4. IFN- $\gamma$, IL-4, IL-10, IL-12, and GAPDH mRNA expression in CD4 ${ }^{+}$and $l p r$ DN T cells from 4-mo-old MRL-lpr/lpr and MRL-lpr/lpr.ll male mice $(A)$ and in $\mathrm{CD}^{+} \mathrm{T}$ cells from 6-mo-old MRL.Yaa and MRL-+/+ male mice $(B)$. PCR was performed with cDNA samples from $\mathrm{CD}^{+}$and $l p r$ DN T cells purified from lymph nodes pooled from three animals for each different MRL lines. PCR products (10 $\mu$ l of the PCR mix) were visualized after electrophoresis through $2 \%$ agarose gels by staining with ethidium bromide (M, molecular weight marker [DNA molecular weight marker VI; Boehringer Mannheim]. -, PCR mix without cDNA). Then, reciprocally diluted samples $(1.2,0.4$, and $0.13 \mu l$ of the PCR mix) from amplified PCR products were applied to nylon membrane and hybridized with corresponding probes. Representative results of three separate experiments are shown.

priate control MRL mice. Although our measurements are not quantitative but only relative between IFN- $\gamma$ and IL-4/IL-10 mRNA expression, the present conclusion is further substantiated by the demonstration that spontaneous and foreign $\mathrm{T}$ cell-dependent antigen-induced productions of IgG2a and IgG3 antibodies, including anti-DNA autoantibodies, are highly significantly elevated, as compared with that of IgG1 antibodies. It should be emphasized that the comparison between MRL-lpr/lpr and MRL-+/+ mice, though differing only in the presence of the $l p r$ mutation, is not appropriate for the present purpose, since the lpr mutation causes defects in the Fas antigen which mediates apoptosis (3), resulting in a marked increase in all the IgG subclasses; this is partly due to an extension of the functional life span of B cells bearing the lpr mutation, as is the case of mice overexpressing a $b c l-2$ transgene in B-lineage cells (30). Nevertheless, it is worth noting that the increase in IgG1 levels in MRL-lpr/lpr vs
MRL- $+/+$ mice is relatively limited, as compared with those of $\operatorname{IgG} 2 \mathrm{a}$ and $\mathrm{IgG} 3$.

It should be mentioned that the lpr DN T cells, a unique T cell subset accumulating in lymph nodes of mice bearing the lpr mutation (23), express substantial levels of IFN- $\gamma$ and IL-10 mRNA, yet we observed remarkable differences in IFN- $\gamma$ mRNA expression, but not in IL-10 mRNA abundance, when mRNA levels in whole lymph nodes were compared between MRL-lpr/lpr and MRL-lpr/lpr.ll mice. This is in fact compatible with the findings that the $l p r$ DN T cell subset is the major population ( $\sim 70 \%$ ) in MRL-lpr/lpr lymph nodes containing the increased presence of the Th1 type cells, while the $l p r$ DN T cells are substantially diminished $(\sim 20 \%)$ in MRL-lpr/lpr.ll lymph nodes, in which $\mathrm{CD} 4^{+} \mathrm{T}$ cells exhibiting the $\mathrm{Th} 2$ predominance are the major population $(\sim 40 \%)(4)$. It can be speculated that a prolonged survival in MRL-lpr/lpr.ll mice may be in part related to the decreased presence of the 

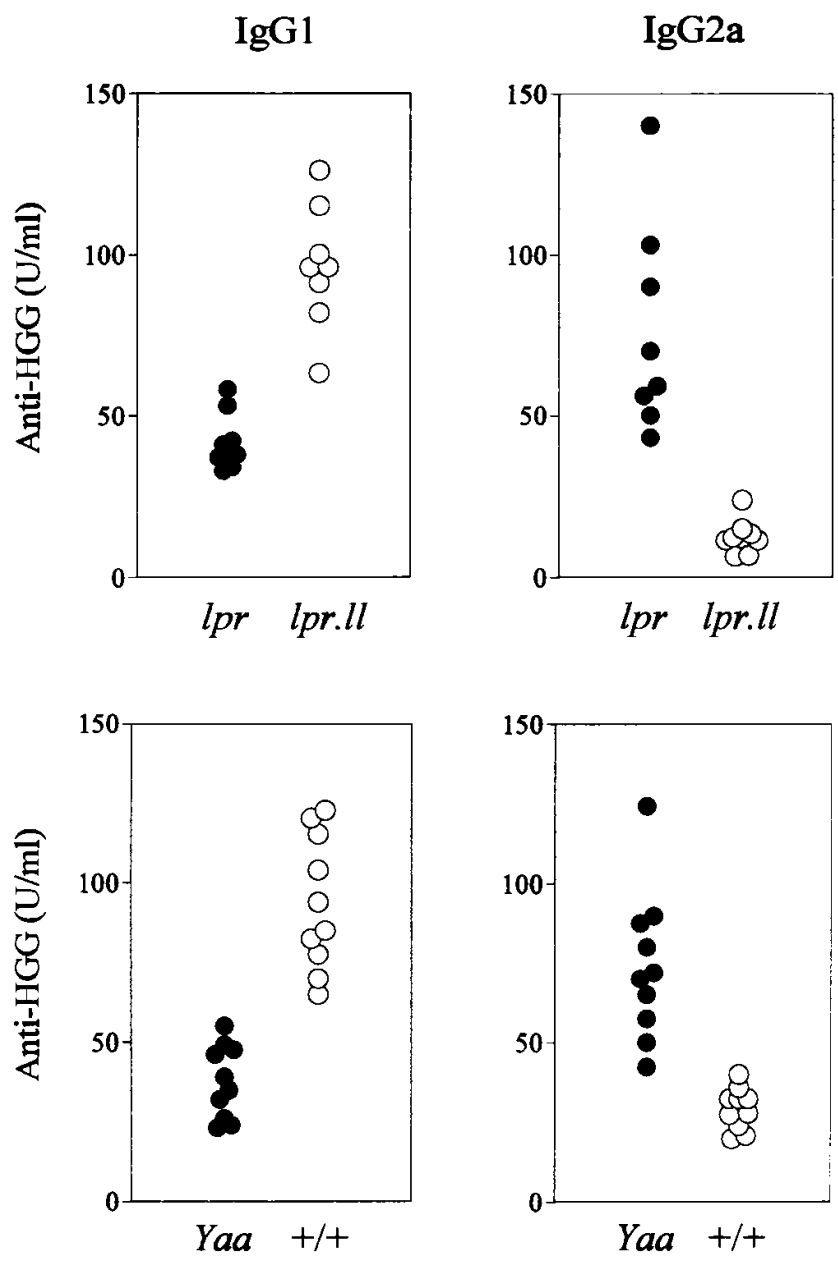

Figure 5. Serum levels of IgG1 and IgG2a anti-HGG antibodies in MRL-lpr/lpr and MRL-lpr/lpr.ll male mice and in MRL.Yaa and MRL- $+/+$ male mice. $400 \mu \mathrm{g}$ of AHGG were intravenously injected into 2-mo-old MRL mice. $10 \mathrm{~d}$ later, serum levels of IgG1 and IgG2a anti-HGG antibodies were determined by ELISA, and results are expressed in $\mathrm{U} / \mathrm{ml}$. IgG1 and IgG2a anti-HGG activities were undetectable in sera from unimmunized MRL mice $(<1 \mathrm{U} / \mathrm{ml})$.

lpr DN T cells, since IFN- $\gamma$ and IL-10 may promote the IgG2a and IgG3 production in MRL-lpr/lpr mice. In fact, IL-10 has been shown to be a potent growth and differentiation factor for activated B cells (31) and to play a significant role in the autoantibody production in murine and human SLE $(32,33)$. However, the contribution by the lpr DN T cells, if any, may not be essential, since our recent study has shown that the spontaneous production of $\operatorname{IgG} 2 \mathrm{a}$ and $\mathrm{IgG} 3$ was not significantly reduced in anti-CD8 mAb-treated MRL-lpr/lpr mice developing an only limited number of the $l p r$ DN T cells (8).

At present it is difficult to answer how the Yaa gene abnormality is associated with the preferential activation of Th1 cells for spontaneous autoimmune and foreign antigen-induced immune responses, and how a possible new mutation present in MRL-lpr/lpr.ll mice leads to the downregulation of Th1 responses in MRL-lpr/lpr mice. An attractive hypothesis is that these mutations may modulate the expression of molecules such as cytokines or adhesion molecules involved in the differentiation of Th0 cells towards Th1 or Th2 cells. In this regard, lack of significant increases in IL-12 mRNA transcripts in lymph nodes and spleens from MRL mice developing an accelerated disease at least argues against the possible involvement of an IL-12-dependent pathway in the observed modulation of Th1/Th2 responses.

It is significant that a relatively enhanced activation of Th1 vs Th2 type cells, leading to an increased production of $\mathrm{IgG} 2 \mathrm{a}$ and $\mathrm{IgG} 3$, but a diminished production of $\operatorname{IgG} 1$, is associated with the acceleration of lupus nephritis in MRL mice bearing the $l p r$ or Yaa gene. This is highly relevant to the immunopathogenesis of lupus nephritis. Since murine $\operatorname{IgG} 2 \mathrm{a}$, but not IgG1, antibodies activate far better the complement system, it is conceivable that the complement activating IgG2a autoantibodies can be more nephritogenic than IgG1 autoantibodies. More significantly, murine IgG3 mAb have been shown to be extremely nephritogenic, generating "wire-loop"-like glomerular lesions (34-36), characteristic in human lupus nephritis, because of their cryoglobulin activity associated with a unique physicochemical property of $\gamma 3$ heavy chain constant region (37). In addition, several studies have provided evidence that the IgG3 production correlates well with the development of murine lupus nephritis $(4,38-40)$. Thus, an enhanced production of IgG3 antibodies is likely to be an important factor for the accelerated development of murine lupus nephritis in MRL mice bearing the lpr or Yaa gene.

The present observation adds a further insight to understanding how the Yaa gene accelerates the development of lupus-like autoimmune disease. We and others have previously shown that the autoimmune enhancing activity of the Yaa gene markedly differ in different lupus-prone mice, depending on the levels of autoantibodies spontaneously produced in the absence of the Yaa gene (2, 41-44). The Yaa gene-mediated enhancement of autoantibody production is most dramatic in mice that spontaneously synthesize relatively low amounts of autoantibodies, but limited or absent in mice that already produce substantially high titers. In addition, the present study revealed that in the latter mice, the Yaa gene apparently modifies the quality of autoantibody responses-upregulation of IgG2a and IgG3 production and downregulation of IgG1 production-by promoting the Th1 responses. Thus, the role of the $Y a a$ gene for the acceleration of lupus-like autoimmune disease is twofold. First, the Yaa gene enhances autoimmune responses against antigens to which mice respond poorly; and second, it promotes Th1 responses over Th2 responses against antigens to which mice respond relatively well, thereby potentiating the production of more nephritogenic autoantibodies.

Our result is consistent with the fact that repeated injections of recombinant IFN- $\gamma$ can accelerate the development of SLE, but the treatment with anti-IFN- $\gamma$ mAb inhibits the progression of SLE in $(\mathrm{NZB} \times \mathrm{NZW}) \mathrm{F} 1$ hybrid mice (18). One of the accelerating effects ascribed to IFN- $\gamma$, in addition to its immune potentiating activity, may be related to the enhanced production of cryogenic IgG3 and complement-activating IgG2a autoantibodies with immunopathological consequences. Although available data have demonstrated a good correlation between the relative predominance of Th1 cells and the accelerated development of lupus-like autoimmune disease, it remains to be determined at what extent Th1 cells are involved in the pathogenesis of SLE. Clearly, studies in lupus-prone mice overexpressing or deficient in Th1 or Th2 cell activity should provide further insight towards our understanding on the respective roles of Th1 and Th2 cells in SLE. 


\section{Acknowledgments}

We thank Dr. Luc Reininger for his critical reading of the manuscript, Mr. Guy Brighouse for his excellent technical help, and Mr. Dominique Wohlwend (Cytofluorography Unit, Faculty of Medicine, University of Geneva) for his help with flow cytometry.

This work was supported by a grant from the Swiss National Foundation for Scientific Research and by a grant for Research on Intractable Diseases from the Ministry of Health and Welfare, Japan.

\section{References}

1. Andrews, B.S., R.A. Eisenberg, A.N. Theofilopoulos, S. Izui, C.B. Wilson, P.J. McConahey, E.D. Murphy, J.B. Roths, and F.J. Dixon. 1978. Spontaneous murine lupus-like syndromes. Clinical and immunopathological manifestations in several strains. J. Exp. Med. 148:1198-1215.

2. Merino, R., T. Shibata, S. de Kossodo, and S. Izui. 1989. Differential effect of the $l p r$ and Yaa genes on the acceleration of lupus-like syndrome in MRL/MpJ mice. Eur. J. Immunol. 19:2131-2137.

3. Watanabe-Fukunaga, R., C.I. Brannan, N.G. Copeland, N.A. Jenkins, and S. Nagata. 1992. Lymphoproliferation disorder in mice explained by defects in Fas antigen that mediates apoptosis. Nature (Lond.). 356:314-317.

4. Fossati, L., S. Takahashi, R. Merino, M. Iwamoto, J.-P. Aubry, M. Nose, C. Spach, R. Motta, and S. Izui. 1993. An MRL/MpJ-lpr/lpr substrain with a limited expansion of $l p r$ double-negative $\mathrm{T}$ cells and a reduced autoimmune syndrome. Int. Immunol. 5:525-532.

5. Santoro, T.J., J.P. Portanova, and B.L. Kotzin. 1988. The contribution of $\mathrm{L} \mathrm{T} 4^{+} \mathrm{T}$ cells to lymphoproliferation and autoantibody production in MRLlpr/lpr mice. J. Exp. Med. 167:1713-1718.

6. Jevnikar, A.M., M.J. Grusby, and L.H. Glimcher. 1994. Prevention of nephritis in major histocompatibility complex class II-deficient MRL-lpr mice. $J$. Exp. Med. 179:1137-1143.

7. Wu, J., T. Zhou, J. Zhang, J. He, W.C. Gause, and J.D. Mountz. 1994. Correction of accelerated autoimmune disease by early replacement of the mutated $l p r$ gene with the normal Fas apoptosis gene in the T cells of transgenic MRL-lpr/lpr mice. Proc. Natl. Acad. Sci. USA. 91:2344-2348.

8. Merino, R., L. Fossati, M. Iwamoto, S. Takahashi, R. Lemoine, N. IbnouZekri, L. Pugliatti, J. Merino, and S. Izui. 1995. Effect of long-term anti-CD4 or anti-CD8 treatment on the development of $l p r \mathrm{CD} 4^{-} \mathrm{CD} 8^{-}$double-negative $\mathrm{T}$ cells and of the autoimmune syndrome in MRL-lpr/lpr mice. J. Autoimmun. 8: 33-45.

9. Wofsy, D. 1986. Administration of monoclonal anti-T cell antibodies retards murine lupus in BXSB mice. J. Immunol. 136:4554-4560.

10. Snapper, C.M., and J.J. Mond. 1993. Towards a comprehensive view of immunoglobulin class switching. Immunol. Today. 14:15-17.

11. Goldman, M., P. Druet, and E. Gleichmann. 1991. Th2 cells in systemic autoimmunity: insights from allogeneic diseases and chemically-induced autoimmunity. Immunol. Today. 12:223-227.

12. Dobashi, K., S. Ono, S. Murakami, Y. Takahama, Y. Katoh, and T. Hamaoka. 1987. Polyclonal B cell activation by a cell differentiation factor, B151-TRF2. III. B151-TRF2 as a B cell differentiation factor closely associated with autoimmune disease. J. Immunol. 138:780-787.

13. Doutrelepont, J.M., M. Moser, O. Leo, D. Abramowicz, M.L. Vanderhaegen, J. Urbain, and M. Goldman. 1991. Hyper IgE in stimulatory graft-versus-host disease: role of interleukin-4. Clin. Exp. Immunol. 83:133-136.

14. Abramowicz, D., J.M. Doutrelepont, P. Lambert, P. Van der Vorst, C. Bruyns, and M. Goldman. 1990. Increased expression of Ia antigens on B cells after neonatal induction of lymphoid chimerism in mice: role of interleukin 4. Eur. J. Immunol. 20:469-477.

15. Schurmans, S., C.H. Heusser, H.Y. Qin, J. Merino, G. Brighouse, and P.H. Lambert. 1990. In vivo effects of anti-IL-4 monoclonal antibody on neonatal induction of tolerance and on an associated autoimmune syndrome. J. Immunol. 145:2465-2473.

16. Snapper, C.M. and W.E. Paul. 1987. Interferon- $\gamma$ and B cell stimulatory factor-1 reciprocally regulate Ig isotype production. Science (Wash. DC). 236: 944-947.

17. Snapper, C.M., T.M. McIntyre, R. Mandler, L.M. T. Pecanha, F.D. Finkelman, A. Lees, and J.J. Mond. 1992. Induction of IgG3 secretion by interferon $\gamma$ : a model for $\mathrm{T}$ cell-independent class switching in response to T cellindependent type 2 antigens. J. Exp. Med. 175:1367-1371.

18. Jacob, C.O., P.H. Van Der Meide, and H.O. McDevitt. 1987. In vivo treatment of $(\mathrm{NZB} \times \mathrm{NZW}) \mathrm{F} 1$ lupus-like nephritis with monoclonal antibody to $\gamma$ interferon. J. Exp. Med. 166:798-803.

19. Luzuy, S., J. Merino, H.D. Engers, S. Izui, and P.H. Lambert. 1986. Autoimmunity after induction of neonatal tolerance to alloantigens: role of B cell chimerism and F1 donor B cell activation. J. Immunol. 136:4420-4426.

20. Bazin, H., F. Cormont, and L. De Clercq. 1986. Purification of rat monoclonal antibodies. Methods Enzymol. 121:638-652.

21. Oi, V.T., and L.A. Herzenberg. 1979. Localization of murine Ig-1b and
Ig-1a (IgG2a) allotypic determinants detected with monoclonal antibodies. Mol. Immunol. 16:1005-1017.

22. Labit, C., and M. Pierres. 1984. Rat monoclonal antibodies to mouse $\operatorname{IgG1}, \operatorname{IgG} 2 \mathrm{a}, \mathrm{IgG} 2 \mathrm{~b}$, and IgG3 subclasses, and kappa chain isotypic determinants. Hybridoma. 3:163-169.

23. Wofsy, D., R.R. Hardy, and W.E. Seaman. 1984. The proliferating cells in autoimmune MRL/lpr mice lack L3T4, an antigen on "helper" T cells that is involved in the response to class II major histocompatibility antigens. J. Immunol. 132:2686-2689.

24. Chirgwin, J.M., A.E. Przybyla, R. MacDonald, and W.J. Rutter. 1979. Isolation of biologically active ribonucleic acid from sources enriched in ribonucleases. Biochemistry. 18:5294-5299.

25. Chomczynski, P., and N. Sacchi. 1987. Single-step method of RNA isolation by acid guanidinium thiocyanate-phenol-chloroform extraction. Anal. Biochem. 162:156-159.

26. Noma, Y., P. Sideras, T. Naito, S. Bergstedt-Lindquist, C. Azuma, E. Severinson, T. Tanabe, T. Kinashi, F. Matsuda, Y. Yaoita, and T. Honjo. 1986 Cloning of cDNA encoding the murine IgG1 induction factor by a novel strategy using SP6 promoter. Nature (Lond.). 319:640-646.

27. Izui, S., V.E. Kelley, K. Masuda, H. Yoshida, J.B. Roths, and E.D. Murphy. 1984. Induction of various autoantibodies by mutant gene $l p r$ in several strains of mice. J. Immunol. 133:227-233.

28. Merino, R., M. Iwamoto, L. Fossati, and S. Izui. 1993. Polyclonal B cell activation arises from different mechanisms in lupus-prone $(\mathrm{NZB} \times \mathrm{NZW}) \mathrm{F} 1$ and MRL/MpJ-lpr/lpr mice. J. Immunol. 151:6509-6516.

29. Trinchieri, G. 1993. Interleukin-12 and its role in the generation of Th1 cells. Immunol. Today. 14:335-338.

30. Strasser, A., S. Whittingham, D.L. Vaux, M.L. Bath, J.M. Adams, S. Cory, and A.W. Harris. 1991. Enforced BCL2 expression in B-lymphoid cells prolongs antibody responses and elicits autoimmune disease. Proc. Natl. Acad. Sci. USA. 88:8661-8665.

31. Rousset, F., E. Garcia, T. Defrance, C. Peronne, D.H. Hsu, R Kastelein, K.W. Moore, and J. Banchereau. 1992. Interleukin-10 is a potent growth and differentiation factor for activated human B lymphocytes. Proc. Natl. Acad. Sci. USA. 89:1890-1893.

32. Ishida, H., T. Muchamuel, S. Sakaguchi, S. Andrade, S. Menon, and M. Howard. 1994. Continuous administration of anti-interleukin 10 antibodies delays onset of autoimmunity in NZB/W F1 mice. J. Exp. Med. 179:305-310.

33. Llorente, L., W. Zou, Y. Levy, Y. Richaud-Patin, J. Wijdenes, J. Alcocer-Varela, B. Morel-Fourrier, J.C. Brouet, D. Alarcon-Segovia, P. Galanaud, and D. Emilie. 1995. Role of interleukin 10 in the B lymphocyte hyperactivity and autoantibody production of human systemic lupus erythematosus. $J$. Exp. Med. 181:839-844.

34. Berney, T., T. Fulpius, T. Shibata, L. Reininger, J. Van Snick, H. Shan, M. Weigert, A. Marshak-Rothstein, and S. Izui. 1992. Selective pathogenicity of murine rheumatoid factors of the cryoprecipitable IgG3 subclass. Int. Immunol. 4:93-99.

35. Lemoine, R., T. Berney, T. Shibata, T. Fulpius, Y. Gyotoku, H. Shimada, S. Sawada, and S. Izui. 1992. Induction of "wire-loop" lesions by murine monoclonal IgG3 cryoglobulins. Kidney Int. 41:65-72.

36. Takahashi, S., J. Itoh, M. Nose, M. Ono, T. Yamamoto, and M. Kyogoku. 1993. Cloning and cDNA sequence analysis of nephritogenic monoclonal antibodies derived from an MRL/lpr lupus mouse. Mol. Immunol. 30: $177-182$.

37. Fulpius, T., F. Spertini, L. Reininger, and S. Izui. 1993. Immunoglobulin heavy chain constant region determines the pathogenicity and the antigen-binding activity of rheumatoid factor. Proc. Natl. Acad. Sci. USA. 90:2345-2349.

38. Takahashi, S., M. Nose, J. Sasaki, T. Yamamoto, and M. Kyogoku. 1991. IgG3 production in MRL/lpr mice is responsible for development of lupus nephritis. J. Immunol. 147:515-519.

39. Steinberg, E.B., T.L. Santoro, T.M. Chused, P.A. Smathers, and A.D Steinberg. 1983. Studies of congenic MRL-lpr/lpr.xid mice. J. Immunol. 131: 2789-2795.

40. Erausquin, C., R. Merino, S. Izui, L. Fernandez-Sueiro, F. Saez, F. Fernandez, V. Rodoriguez-Valverde, and J. Merino. 1995. Therapeutic effect of early thymic irradiation in $(\mathrm{NZB} \times \mathrm{NZW}) \mathrm{F} 1$ mice, associated with a selective decrease in the levels of IgG3 and gp70-anti-gp70 immune complexes. Cell. Immunol. 161:207-212.

41. Izui, S., K. Masuda, and H. Yoshida. 1984. Acute SLE in F1 hybrids between SB/Le and NZW mice: prominently enhanced formation of gp70 immune complexes by a Y chromosome-associated factor from SB/Le mice. J. Immunol. 132:701-704.

42. Hudgins, C.C., R.T. Steinberg, D.M. Klinman, M.P.J. Reeves, and A.D. Steinberg. 1985. Studies of consomic mice bearing the Y chromosome of the BXSB mouse. J. Immunol. 134:3849-3854.

43. Izui, S., M. Higaki, D. Morrow, and R. Merino. 1988. The Y chromosome from autoimmune $\mathrm{BXSB} / \mathrm{MpJ}$ mice induces a lupus-like syndrome in $(\mathrm{NZW} \times \mathrm{C} 57 \mathrm{BL} / 6) \mathrm{F} 1$ male mice, but not in C57BL/6 male mice. Eur. J. Immunol. 18:911-915.

44. Fossati, L., R. Merino, M. Iwamoto, and S. Izui. 1995. Selective accelerating effect of the Yaa gene on immune responses against self and foreign antigens. Eur. J. Immunol. 25:166-173. 